Vol. 1 No. 2, Juni 2021, hlm. $153-160$

DOI: https://doi.org/10.33330/jutsi.v2i1.1162

Available online at http://jurnal.stmikroyal.ac.id/index.php/jutsi

\title{
PENCARIAN AGEN HNI-HPAI TERDEKAT WILAYAH KISARAN MENGGUNAKAN METODE HAVERSINE
}

\author{
Bagus Lesmana', Havid Syafwan ${ }^{2 *}$, Afdhal Syafnur ${ }^{3}$ \\ ${ }^{1}$ Mahasiswa Prodi Studi Sistem Informasi, STMIK Royal \\ ${ }^{2}$ Prodi Manajemen Informatika, STMIK Royal \\ ${ }^{3}$ Prodi Sistem Informasi, STMIK Royal \\ *email: havid_syafwan@yahoo.com
}

\begin{abstract}
HNI-HPAI is a network of halal-based companies in Indonesia that sell herbal products. HPAI has a variety of products, such as herbal medicine products for health, household products, and others. On the other hand, HPAI also has a certificate issued by the National Syari'ah CouncilMUI which has complied with sharia principles in meeting the needs of the community, which currently pays attention not only top quality but also to its halalness. This study discusses the search for HNI-HPAI agents in Kisaran City who have difficulty finding the location of these agents, especially for people outside the Kisaran Area and buyers who do not know the location and the closest route for existing HNI-HPAI agents. in the Range Region. The results of this study are a web-based Geographic Information System for searching the nearest HNI-HPAI agent in the Kisaran area using the haversine method.
\end{abstract}

Keywords: Geographical Information System; HNI-HPAI; Nearest Route Search; Haversine Method

\begin{abstract}
Abstrak: HNI-HPAI merupakan jaringan perusahaan berbasis halal di Indonesia yang menjual produk-produk herbal. HPAI mempunyai berbagai macam produk, seperti produk obat-obatan herbal untuk kesehatan, produk kebutuhan rumah tangga, dan lain-lain. Disisi lain HPAI juga sudah memiliki sertifikat yang dikeluarkan Dewan Syari'ah Nasional-MUI dimana sudah memenuhi prinsip syari'ah dalam memenuhi kebutuhan masyarakat yang saat ini tidak hanya memperhatikan kualitasnya saja, tetapi juga kehalalannya. Penelitian ini membahas mengenai pencarian agen-agen HNI-HPAI yang ada di Kota Kisaran yang memiliki masalah sulitnya dalam menemukan lokasi agen-agen tersebut khususnya bagi masyarakat yang ada di luar Wilayah Kisaran serta pembeli tidak tahu lokasi serta rute terdekat agen HNI-HPAI yang ada di Wilayah Kisaran. Hasil dari penelitian ini berupa Sistem Informasi Geografis pencarian agen HNI-HPAI terdekat Wilayah Kisaran berbasis web menggunakan metode haversine.
\end{abstract}

Kata kunci: Sistem Informasi Geografis; HNI-HPAI; Pencarian Rute Terdekat; Metode Haversine 
Vol. 1 No. 2, Juni 2021, hlm. $153-160$

DOI: https://doi.org/10.33330/jutsi.v2i1.1162

Available online at http://jurnal.stmikroyal.ac.id/index.php/jutsi

\section{PENDAHULUAN}

Di era digital saat ini dimana serba menggunakan sistem informasi, banyak model yang kita jumpai dalam keseharian yang dapat memberikan berbagai macam informasi. Dengan adanya informasi, maka akan muncul banyak ide-ide baru terhadap penciptaan model dalam merancang aplikasi-aplikasi yang sangat berguna dalam melakukan aktivitas pada berbagai aspek kehidupan masyarakat. Pemetaan sistem informasi geografis atau yang disingkat dengan GIS adalah model dari sistem informasi yang banyak diterapkan dalam menghasilkan berbagai perencanaan, analisis serta keputusan.

GIS dapat dipakai sebagai alat bantu utama yang menarik, bersifat interaktif, serta menantang pada berbagai usaha-usaha dalam menambah pemahaman, pendidikan dan pembelajaran terhadap ide atau konsep lokasi, ruang, kependudukan, dan unsur geografis yang ada di atas permukaan bumi. Salah satu GIS yang dibutuhkan pada saat ini adalah menemukan lokasi bisnis penjualan suatu produk. Salah satu perusahaan bisnis halal network di Indonesia hanya berfokus pada produk-produk herbal yaitu HNI-HPAI. HPAI mempunyai berbagai macam produk seperti produk kesehatan berupa obat-obatan herbal, produk kebutuhan rumah tangga, dan lain-lainya. Dewan Syari'ah Nasional-MUI memberikan sertifikat kepada HPAI karena sudah memenuhi konsep syari'ah dalam memenuhi kebutuhan masyarakat yang sekarang ini tidak hanya mengutamakan produk yang berkualitas saja, tetapi juga terjamin kehalalannya [1].

GIS merupakan sebuah sistem komputer yang dipakai dalam memanipulasi dan menyimpan berbagai informasi yang berkaitan dengan geografi. Sistem Informasi Geografis dirancang untuk mengumpulkan, menyimpan, dan menganalisis objek-objek serta fenomena-fenomena dimana lokasi geografi merupakan karakteristik yang perlu untuk dianalisis. Dengan begitu, GIS merupakan sistem komputer yang mempunyai kehandalan untuk menangani data yang bereferensi geografi, manajemen data (menyimpan dan memanggil data), analisis serta manipulasi data keluaran [2].

Lokasi merupakan tempat dimana suatu usaha atau aktifitas usaha dilakukan Faktor penting dalam pengembangan suatu usaha adalah letak lokasi terhadap daerah perkotaan [3]. Pada lokasi Kota Kisaran, HNI-HPAI memiliki agen di beberapa titik lokasi. Pencarian lokasi agen HNI-HPAI yang ada di Kota Kisaran masih sulit untuk ditemukan khususnya bagi masyarakat luar Kota Kisaran dan pembeli tidak tahu lokasi agen HNI-HPAI terdekat yang ada di Wilayah Kisaran. Agen HNI-HPAI sudah melakukan promosi pada media masa seperti majalah, surat kabar dan brosur. Tetapi cara tersebut belum mampu untuk memberikan informasi lokasi penjualan produk HNI-HPAI kepada pelanggan lokal maupun asing. Biasanya para pelanggan yang sudah terbiasa berbelanja di agen langganannya, apabila agen tersebut kehabisan stok produk yang dicari oleh pelanggan, biasanya para pelanggan tersebut kesulitan mencari agen HNI-HPAI yang ada di Wilayah Kisaran

Dari penjelasan tersebut di atas, maka penulis tertarik untuk merancang sebuah sistem informasi geografis dalam pencarian agen HNI-HPAI terdekat wilayah Kisaran menggunakan metode haversine. Adapun tujuan dari kegiatan penelitian ini adalah dapat memberikan informasi kepada para pelanggan produk HNI-HPAI dalam mencari lokasi agen terdekat dan memudahkan semua kalangan pengguna smartphone dan pelanggan HNI- 
Vol. 1 No. 2, Juni 2021, hlm. $153-160$

DOI: https://doi.org/10.33330/jutsi.v2i1.1162

Available online at http://jurnal.stmikroyal.ac.id/index.php/jutsi

HPAI baik masyarakat Kota Kisaran maupun masyarakat di luar Kota Kisaran dalam pencarian lokasi agen HNI-HPAI dengan cepat dan akurat.

\section{METODE}

Pada Penelitian ini menggunakan metode Haversine yaitu persamaan yang dipakai pada navigasi, yang memberikan jarak lingkaran besar antara dua titik pada permukaan bumi berdasarkan bujur dan lintang. Formula Haversine digunakan untuk mengetahui jarak antar dua titik dengan memperhitungkan bahwa bumi bukanlah sebuah bidang datar namun adalah sebuah bidang yang memilki derajat kelengkungan [4]. Metode haversine merupakan sebuah metode dalam menghitung jarak dari daerah asal ke tempat tujuan. Proses perhitungan jarak memerlukan titik koordinat latitude dan longitude tempat asal serta titik koordinat latitude dan longitude tempat tujuan [5]. Langkah-Langkah pencarian agen HPAI terdekat sebagai berikut: (1) Langkah pertama harus mengetahui titik koordinat user dan titik koordinat agen-agen HPAI yang ada di Wilayah Kisaran., (2) Titik koordinat user dan agen jika sudah diketahui, maka melakukan proses selanjutnya yaitu melakukan perbandingan jarak terdekat dengan menggunakan rumus $=6371 * A \cos (\operatorname{Cos}(\operatorname{Radians}(\mathrm{Lat}$ 1) $) * \operatorname{Cos}(\operatorname{Radians}(\operatorname{Lat} 2)) * \operatorname{Cos}(\operatorname{Radians}(\operatorname{Long} 2) \operatorname{Radians}(\operatorname{Long} 1))+\operatorname{Sin}(\operatorname{Radians}(\operatorname{Lat} 1)) * \operatorname{Sin}(\operatorname{ad}$ ians(Lat2))).

$$
\begin{array}{ll}
\text { Dimana: } & \\
6371 & \text { : jari-jari bumi } \\
\text { Lat1 } & \text { : latitude user } \\
\text { Long1 } & \text { : longitude user } \\
\text { Lat2 } & \text { : latitude agen } \\
\text { Long2 } & \text { : longitude agen }
\end{array}
$$

Jika dalam perbandingan tersebut dijumpai jarak yang lebih kecil, maka sistem akan mengambil jarak yang lebih kecil tersebut. Proses perbandingan berlanjut hingga semua jarak agen HPAI selesai diperbandingkan. Jarak yang memiliki nilai paling kecil akan dijadikan sebagai solusi untuk menentukan jarak terpendek. Tahap pengujian manual pencarian agen HNI-HPAI terdekat Wilayah Kisaran dengan haversine dengan microsoft excel, diperlukan untuk menganalisa hasil lokasi. Berikut data agen HNI-HPAI yang ada di Wilayah Kisaran Langkah-langkah perhitungan dari sistem pencarian agen HNI-HPAI terdekat adalah : (1) Mencari lokasi awal pencarian, (a) Lokasi : STMIK ROYAL KISARAN, (b) Latitude: 2,963367, (c) Longitude: 99,632646. Pencarian jarak dari titik dengan objek di dalam data training dapat dilihat pada tabel 1 Untuk mencari jarak antara titik user dan agen terdekat dapat menggunakan rumus $=6371^{*} A \cos (\operatorname{Cos}($ Radians $($ Lat 1))*Cos(Radians(Lat2) $) * \operatorname{Cos}(\operatorname{Radians}(\operatorname{Long} 2) \operatorname{Radians}(\operatorname{Long} 1))+\operatorname{Sin}(\operatorname{Radians}(\operatorname{Lat} 1)) * \operatorname{Sin}(\mathrm{R}$ $\operatorname{adians}($ Lat2))). 
Vol. 1 No. 2, Juni 2021, hlm. $153-160$

DOI: https://doi.org/10.33330/jutsi.v2i1.1162

Available online at http://jurnal.stmikroyal.ac.id/index.php/jutsi

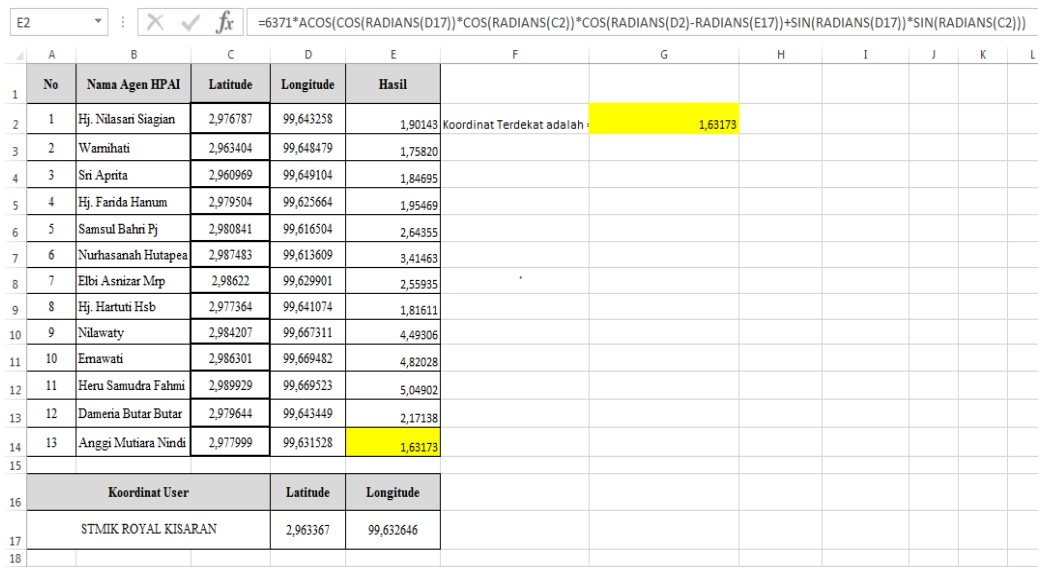

Gambar 1. Hasil Pencarian Agen HNI-HPAI Terdekat

Dari hasil perhitungan pencarian agen HPAI terdekat dengan menggunakan metode haversine di atas adalah agen Anggi Mutiara Nindi.

\section{HASIL DAN PEMBAHASAN}

Penerapan dari aplikasi ini berkaitan dengan tampilan-tampilan yang ada di SIG pencarian agen HNI-HPAI terdekat Wilayah Kota Kisaran menggunakan metode haversine. Ketika user dan admin membuka sistem untuk pertama kali, maka user dan admin akan masuk ke halaman utama sistem. Berikut tampilan halaman utama SIG pencarian agen HNI-HPAI terdekat Wilayah Kisaran menggunakan metode haversine.

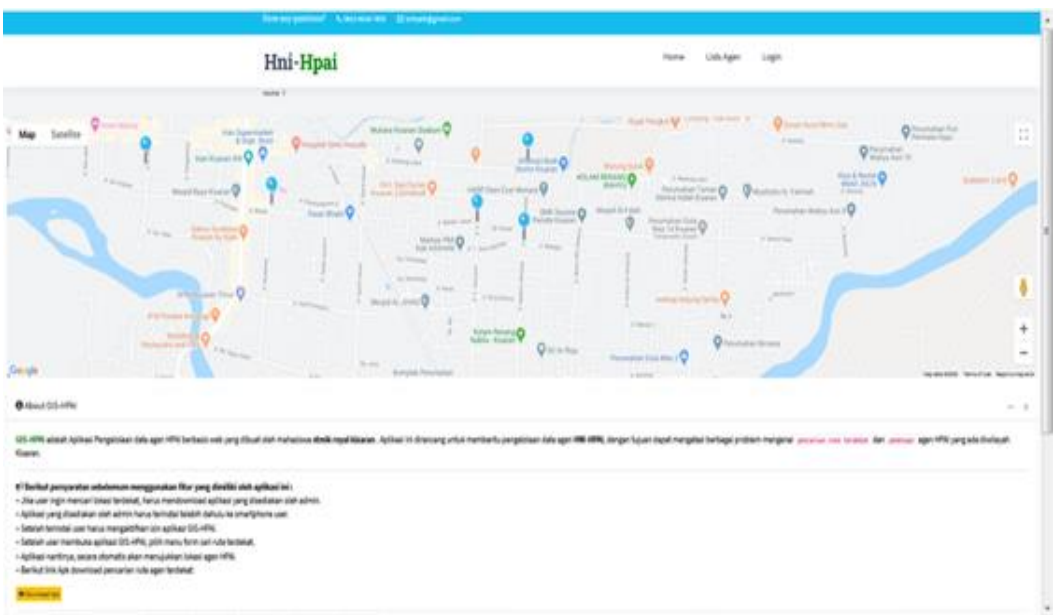

Gambar 2. Halaman Utama 
Vol. 1 No. 2, Juni 2021, hlm. 153 - 160

DOI: https://doi.org/10.33330/jutsi.v2i1.1162

Available online at http://jurnal.stmikroyal.ac.id/index.php/jutsi

Menu lists agen user merupakan halaman yang menampilkan data agen HPAI yang ada di Wilayah Kisaran, halaman ini juga berisikan tombol detail.

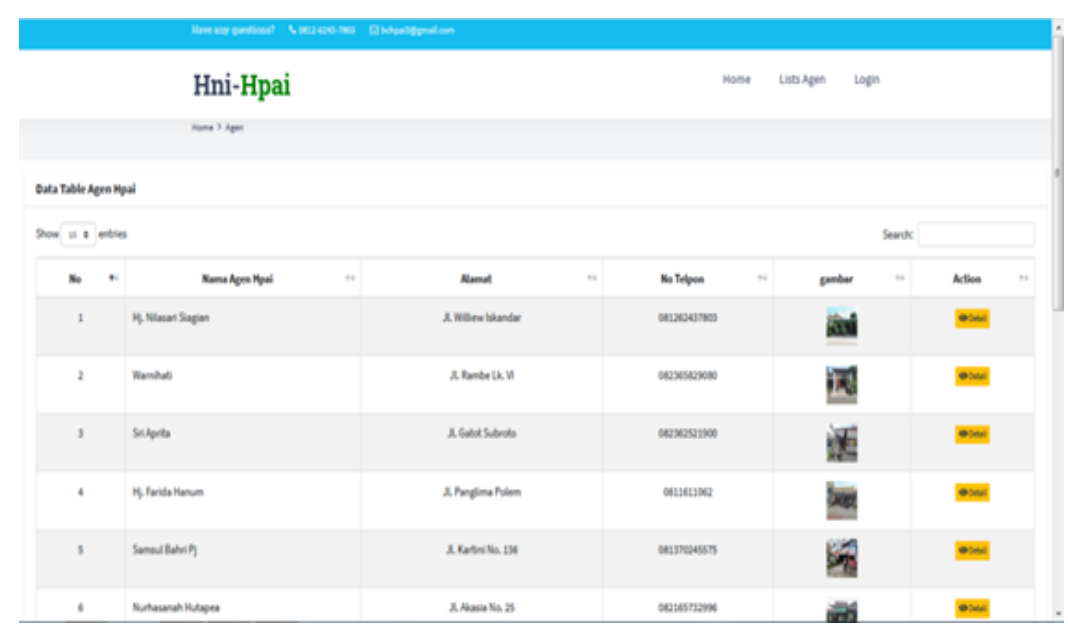

Gambar 3. Menu Lists Agen User

Menu login merupakan halaman untuk klarifikasi hak admin melakukan login untuk masuk ke sistem. Setelah login, admin akan di arahkan ke halaman home admin.

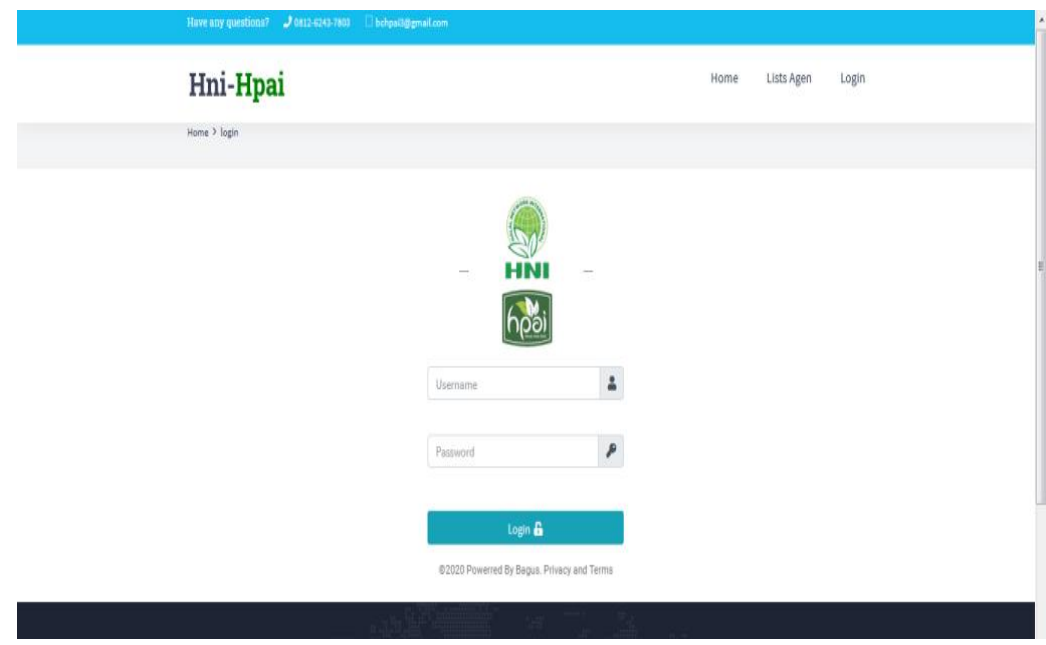

Gambar 4. Menu Login

Menu cari agen terdekat merupakan halaman sistem yang nantinya secara otomatis akan menunjukkan lokasi agen terdekat. 
Vol. 1 No. 2, Juni 2021, hlm. $153-160$

DOI: https://doi.org/10.33330/jutsi.v2i1.1162

Available online at http://jurnal.stmikroyal.ac.id/index.php/jutsi

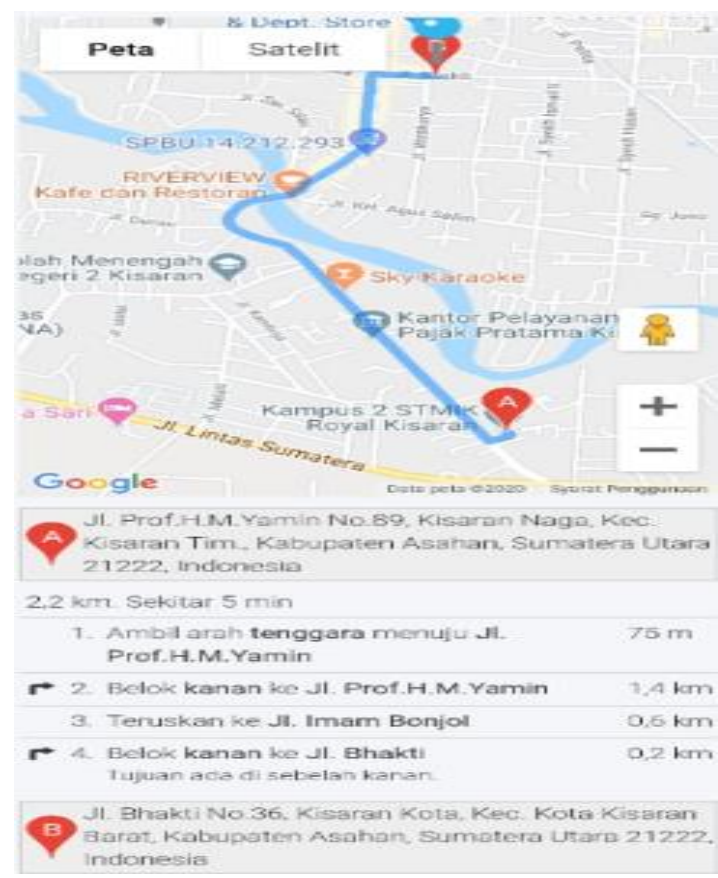

Gambar 5. Menu Cari Agen Terdekat

Menu utama admin merupakan, halaman awal ketika admin berhasil login ke sistem.

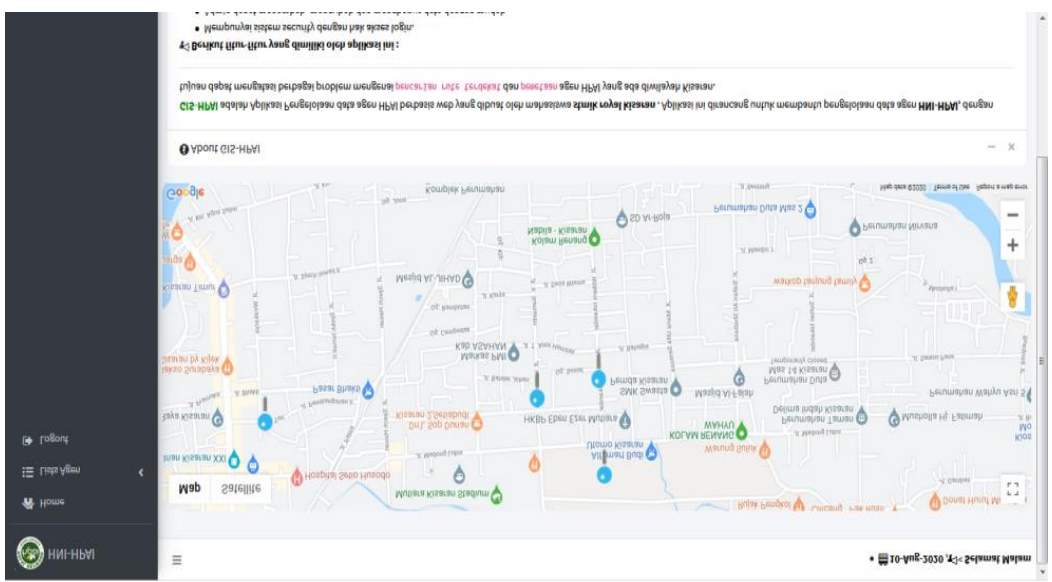

Gambar 6. Menu Utama Admin

Menu lists agen admin merupakan halaman yang menampilkan data-data agen HPAI serta tombol untuk mengolah data seperti, input data, edit data, detail dan hapus. 
Vol. 1 No. 2, Juni 2021, hlm. $153-160$

DOI: https://doi.org/10.33330/jutsi.v2i1.1162

Available online at http://jurnal.stmikroyal.ac.id/index.php/jutsi

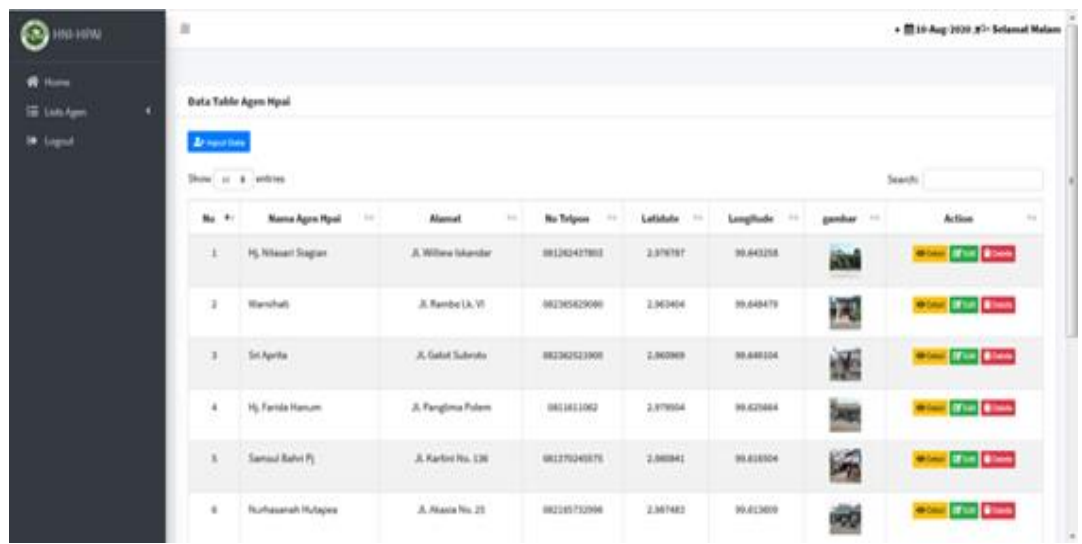

Gambar 7. Menu Lists Agen Admin

Menu input data merupakan halaman dimana admin menambahkan data agen HPAI.

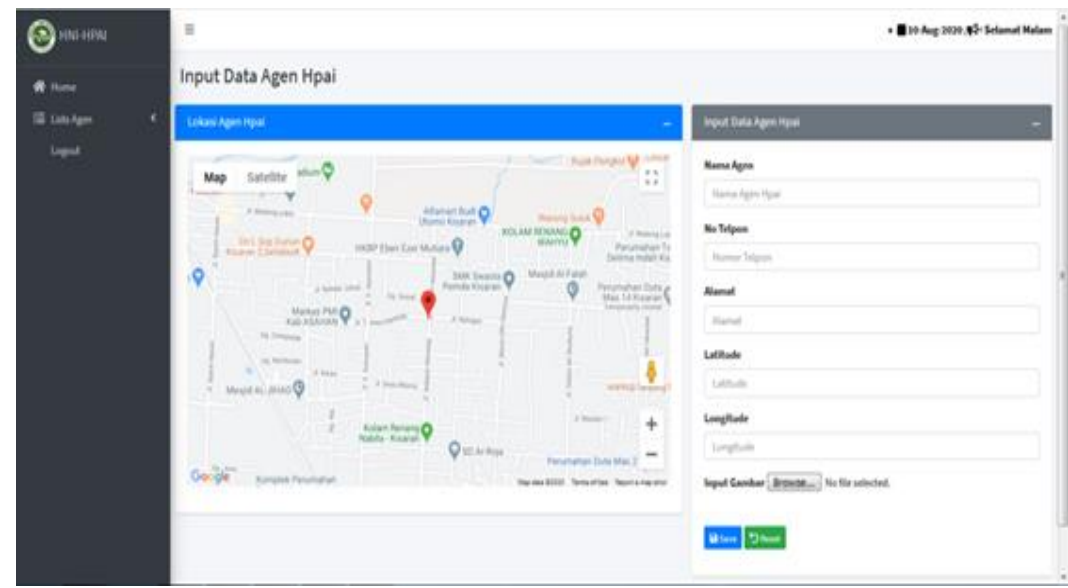

Gambar 8. Menu Input Data

\section{SIMPULAN}

Berdasarkan implementasi dan pengujian yang dilakukan selama membuat Sistem Informasi Geografis Pemilihan Rute Terdekat Agen HNI-HPAI Wilayah Kisaran ini, maka diperoleh kesimpulan sebagai berikut: (1) Sistem Informasi Geografis pencarian agen HNIHPAI terdekat Wilayah Kisaran ini berbasis web disertai dengan informasi yang berkaitan dengan tempat agen HPAI di Wilayah Kisaran., (2) Informasi yang disajikan mengenai informasi agen HPAI di wilayah Kisaran berupa nama agen, nomor telpon, alamat, rute terdekat, serta foto alamat agen., (3) Dengan adanya aplikasi pencarian agen HNI-HPAI terdekat Wilayah Kisaran ini memudahkan pengguna dalam mengetahui titik letak agen HPAI dan jalur terdekatnya. 
Vol. 1 No. 2, Juni 2021, hlm. $153-160$

DOI: https://doi.org/10.33330/jutsi.v2i1.1162

Available online at http://jurnal.stmikroyal.ac.id/index.php/jutsi

\section{DAFTAR PUSTAKA}

[1] B. Saragih, MM., "Pengaruh Kualitas Produk Dan Promosi Terhadap Keputusan Pembelian," J. Manaj. Bisnis Krisnadwipayana, vol. 6, no. 3, 2018, doi: 10.35137/jmbk.v6i3.220.

[2] W. Ambarwati and Y. Johan, "Sejarah Dan Perkembangan Ilmu Pemetaan," J. Enggano, vol. 1, no. 2, pp. 80-82, 2016, doi: 10.31186/jenggano.1.2.80-82.

[3] S. Bagian, J. Kejahatan, and K. B. Android, "Kriminalitas Pada Ditreskrimum Polda."

[4] Y. Yulianto, R. Ramadiani, and A. H. Kridalaksana, "Penerapan Formula Haversine Pada Sistem Informasi Geografis Pencarian Jarak Terdekat Lokasi Lapangan Futsal," Inform. Mulawarman J. Ilm. Ilmu Komput., vol. 13, no. 1, p. 14, 2018, doi: 10.30872/jim.v13i1.1027.

[5] S. N. Anwar, I. Nugroho, and E. Supriyanto, "Model Rute dan Peta Interaktif Posyandu di Kota Semarang Menggunakan Geolocation dan Haversine Berbasis Mobile Android," Pros. Semin. Nas. Multi Disiplin Ilmu Call Pap. UNISBANK, vol. 20, no. 1, pp. 978-979, 2015. 